\title{
El uso de las lenguas cooficiales en el Senado español
}

\author{
Rafael D. Agulló Mateu \\ Profesor Asociado de Ciencia Política y de la Administración \\ Universidad de Alicante
}

\begin{abstract}
Sumario: I. APROXIMACIÓN.-II. LA COOFICIALIDAD LINGÜÍSTICA EN EL ESTADO ESPAÑOL.-III. BREVE REFERENCIA AL SENADO COMO CÁMARA DE REPRESENTACIÓN TERRITORIAL.-IV. LAS LENGUAS ESPAÑOLAS COOFICIALES Y SU USO EN EL SENADO: 1 Breve recorrido histórico. A) Antes de la aprobación de la Constitución de 1978. B) Aprobación de la Constitución de 1978. C) La reforma del Reglamento del Senado de 3 de mayo de 1994. D) Reforma del Reglamento del Senado sobre la ampliación del uso de las lenguas cooficiales en el Senado de 4 de julio de 2005. 2. Algunas reflexiones sobre el uso de las lenguas cooficiales en el Senado español.- $V$. RECAPITULACIÓN Y CONCLUSIONES.-VI. BIBLIOGRAFÍA.
\end{abstract}

\section{APROXIMACIÓN}

El presente estudio ${ }^{1}$ pretende esbozar cual es el régimen de uso en el Senado español de las distintas lenguas declaradas cooficiales, junto al castellano, en alguna de las Comunidades Autónomas.

Comenzaremos realizando un primer acercamiento a la realidad plurilinguie que caracteriza a nuestro país, viendo como ello se proyecta sobre la realidad jurídico-aministrativa del Estado y obliga a que sean tenidas en cuenta las sensibilidades linguísticas a la hora de legislar, administrar y gobernar.

Abordaremos igualmente la relación directa que se da entre el régimen de cooficialidad linguística y el sistema español de descentralización políticoadministrativa, de forma que las citadas lenguas cooficiales se identifican con unidades políticas concretas (Comunidades Autónomas).

Ello nos llevará a comprender como el régimen de pluralidad de lenguas que se da en España se encuentra estrechamente vinculado a su estructura territorial, por lo que el uso de las mismas en una Institución inspirada, precisamente, en ese principio de territorialidad, como ocurre, al menos de forma hipotética, es nuestra Cámara Alta, convierte en un tema de sumo interés la utilización de dichas lenguas cooficales en el seno de la citada Institución.

Por ello, dedicaremos los diferentes apartados de este estudio a analizar el régimen de utilización de las lenguas cooficiales en el Senado español, su evolución, su realidad actual y a intentar vislumbrar cuales podrían ser sus

\footnotetext{
${ }^{1}$ Quisiera mostrar mi agradecimiento a la Profesora María Sánchez-Roca Ruiz, por sus magníficas recomendaciones y sus acertados comentarios en la revisión del texto.
} 
posibilidades de futuro, aportando elementos para el debate y exponiendo una serie de datos e interpretaciones que consideramos pueden resultar de interés a la hora de conocer mejor el funcionamiento de uno de los principales órganos constitucionales del Estado, el Senado.

\section{LA COOFICIALIDAD LINGÜÍSTICA EN EL ESTADO ESPAÑOL}

Tras un largo periodo de aletargamiento oficial y, en ocasiones, social, de las diferentes lenguas españolas distintas al castellano que se vivió en muestro país durante la dictadura franquista, asistimos a un renacimiento del interés y reivindicación de las mismas como parte o elemento de toque del resurgimiento cultural que en diferentes partes del territorio nacional permitía la nueva situación socio-política.

Así, se convirtieron en verdadero punto de inflexión de esta realidad creciente el tenor del artículo 2 de nuestra Constitución ${ }^{2}$, aprobada en esas fechas, el cual reconocían de forma abierta las distintas nacionalidades que conforman el Estado español, y el del artículo 3, que determinaba que, aún siendo el castellano la lengua oficial del Estado, se reconocía la cooficialidad de las demás lenguas españolas en las Comunidades Autónomas que así lo determinasen por vía estatutaria.

Se abrió así un nuevo período en el que las culturas y lenguas gallega, vasca, catalana y valenciana, entre otras, comenzaron a recobrar un protagonismo perdido tiempo atrás principalmente por consideraciones de tipo político.

En esa época de cambios, pronto fue materializándose, por medio de la articulación del Estado Autonómico, una verdadera inquietud por el redescubrimiento de lo autóctono, de forma que los nuevos entes territoriales dieron especial importancia al reconocimiento y oficialización de sus elementos singulares. Entre dichos elementos, y por lo que respecta a aquellas Comunidades Autónomas que contaban con un idioma propio suficientemente desarrollado, cobró especial importancia la recuperación del mismo, el cual, en la mayoría de los casos, aunque había continuado su uso de forma más o menos habitual, se encontraba fuertemente desestructurado y fuera de toda utilización oficial o educativa.

Varias fueron la Comunidades Autónomas que, en el acto mismo de su constitución, sus Estatutos de Autonomía, dotaron de carácter cooficial, junto al castellano, a la lengua hablada por gran número de sus habitantes y que era entendida como propia.

\footnotetext{
${ }^{2}$ Art. 2 CE: «La Constitución se fundamenta en la indisoluble unidad de la Nación española, patria común e indivisible de todos los españoles, y reconoce y garantiza el derecho a la autonomía de las nacionalidades y regiones que la integran y la solidaridad entre todas ellas».
} 
Así ocurrió, por ejemplo, en el Estatuto del País Vasco ${ }^{3}$, cuyo artículo 6 determina que, «el euskera, lengua propia del Pueblo Vasco, tendrá, como el castellano, carácter de lengua oficial en Euskadi». También se recogió esta idea en la norma básica gallega ${ }^{4}$, la cual, en su artículo 5.1 señala que, «la lengua propia de Galicia es el gallego», añadiendo en el 5.2 que «los idiomas gallego y castellano son oficiales en Galicia». Igualmente se hizo por parte de la Comunidad Valenciana ${ }^{5}$, en artículo 7 (ahora 6) de cuyo Estatuto de Autonomía podía leerse que, «los dos idiomas oficiales de la Comunidad Autónoma son el valenciano y el castellano.(...) La Generalidad Valenciana garantizará el uso normal y oficial de las dos lenguas».

En unos términos similares se expresaron otras Comunidades Autónomas como Navarra ${ }^{6}$, Cataluña ${ }^{7}$ o Illes Balears ${ }^{8}$, siendo ello claro indicativo del espíritu de reivindicación de la lengua autóctona que latía en el ánimo de los estatuyentes, lo que llevó, en el caso de Illes Balears, a establecer como única denominación oficial de la Comunidad, la hecha en catalán.

La declaración de cooficialidad de las lenguas propias suponía una serie de efectos sobre el régimen legal y administrativo que obligaba a los nuevos ejecutivos y legislativos regionales, pero no sólo ellos, sino también a los órganos jurídico-administrativos centrales, a tomar conciencia de la nueva realidad legal y social que el reconocimiento plurilingüístico significaba y actuar ante ello.

Desde entonces se ha asistido a un continuo proceso de toma en consideración de la realidad plurilingüe del Estado español, plurilingüe al menos en algunos territorios del mismo, y aunque ha sido, y es, un camino que en ocasiones ha sido dificultoso recorrer, es lo cierto que hoy en día vemos como nuestra realidad jurídica y social se van haciendo eco de ello poco a poco.

Sin desconocer que todavía queda camino por recorrer, sí que puede afirmarse que la sensibilidad lingüística ha ido llegado a la legislación nacional, pudiendo encontrarse continuas referencias a este reconocimiento de las lenguas distintas al castellano en infinidad de normas legales de la más diversa consideración. Sirvan a modo de ejemplo, y sin carácter exhaustivo, las siguientes:

- Artículo 35.d) Ley 30/1992, de 26 de noviembre de Régimen Jurídico de las Administraciones Públicas y del Procedimiento Administrativo Común: «Los ciudadanos, en sus relaciones con las Administraciones Pú-

\footnotetext{
${ }^{3}$ LO 3/1979, 18 de diciembre, Estatuto de Autonomía para el País Vasco.

${ }^{4}$ LO 1/1981, 6 de abril, Estatuto de Autonomía de Galicia.

${ }^{5}$ LO 5/1982, 1 de julio, Estatuto de Autonomía de la Comunidad Valenciana. Modificado profundamente por la LO $1 / 2006$, de 10 de abril.

${ }^{6}$ LO 13/1982, 10 de agosto, de Reintegración y Amejoramiento del Régimen Foral de Navarra, art. 9.2.

${ }^{7}$ LO 4/1979, 18 de diciembre, Estatuto de Autonomía de Cataluña, art. 3. Ahora art. 6, tras la aprobación de la LO 6/2006, de 19 de julio.

${ }^{8}$ LO 2/1983, 25 de febrero, Estatuto de Autonomía de Illes Balears, art. 3. Ahora art. 4 tras la aprobación de la LO 1/2007, de 28 de febrero.
} 
blicas, tienen los siguientes derechos: (...) a utilizar las lenguas oficiales en el territorio de su Comunidad Autónoma, de acuerdo con lo previsto en esta Ley y en el resto del Ordenamiento Jurídico».

- Artículo 229.3.3 de la Ley Orgánica 6/1985, de 1 de julio, del Poder Judicial: «Las partes, sus representantes y quienes les dirijan, así como los testigos y peritos, podrán utilizar la lengua que sea también oficial en la Comunidades Autónomas en cuyo territorio tengan lugar las actuaciones judiciales, tanto en manifestaciones orales como escritas».

- Artículo 23 de la Ley de 8 de junio de 1957 del Registro Civil (modificada por Ley 12/2005): «Los asientos se realizarán en lengua castellana o en la lengua oficial propia de la Comunidad Autónoma en que radique el Registro Civil, según la lengua en que esté redactado el documento o en que se realice la manifestación. Si el documento es bilingüe, se realizarán en la lengua indicada por quien lo presente al Registro. Todo ello, siempre que la legislación lingüística de la Comunidad Autónoma prevea la posibilidad de redacción de los asientos de los registros públicos en idioma cooficial distinto del castellano».

- Artículo 8 de la Ley Orgánica 3/1984, de 26 de marzo, Reguladora de la Iniciativa Legislativa Popular, la cual, al referirse a los pliegos en los que se recogerán las firmas, determina que los mismos: «deberán estar escritos en castellano. Para la recogida de firmas en el territorio de una Comunidad Autónoma con otra lengua cooficial podrá utilizarse, conjuntamente, esta otra lengua».

- Artículo 5.1 de la Ley Orgánica 4/2001, de 12 de noviembre, reguladora del derecho de petición: «En el ámbito territorial de las Comunidades Autónomas cuyos Estatutos establezcan la cooficialidad lingüística, los peticionarios tendrán derecho a formular sus peticiones a la Administración General del Estado o a los organismos públicos vinculados o dependientes de ella en cualquiera de las lenguas oficiales y a obtener respuesta en la lengua de su elección».

- Disposición Adicional Cuarta del Real Decreto Legislativo 339/1990, de 2 de marzo, por el que se aprueba el Texto Articulado de la Ley sobre Tráfico, Circulación de Vehículos a Motor y Seguridad Vial (añadida por la Ley 17/2005): «En aquellas Comunidades Autónomas que tengan una lengua cooficial, los permisos y licencias de conducción se redactarán además de en castellano en dicha lengua».

Vemos como nos encontramos ante un proceso cierto de integración de las lenguas cooficiales en la vida pública española ${ }^{9}$, proceso impulsado principalmente, ello es obvio, por los representantes políticos de las distintas Comunidades Autónomas con lengua cooficial reconocida en sus Estatutos,

\footnotetext{
${ }^{9}$ Durante la corrección del presente artículo fue aprobado el real decreto 905/2007, de 6 de julio, por el que se crean el Consejo de las lenguas cooficiales en la Administración General del estado y la Oficina para las Lenguas Cooficiales.
} 
lo que se puede comprobar si realizamos un análisis de las propuestas y enmiendas presentadas por tales representantes políticos a los diferentes proyectos legislativos de índole nacional.

$\mathrm{Y}$ en este proceso no es extraño que se plantease la necesaria presencia de estas lenguas cooficiales en los órganos centrales del Estado, al menos, y dentro de una lógica totalmente comprensible, en aquellos que responden a una supuesta, y repetimos supuesta, representación de los diferentes territorios que conforman nuestro país. Nos estamos refiriendo, es fácil comprenderlo, al Senado.

\section{BREVE REFERENCIA AL SENADO COMO CÁMARA DE REPRESENTACIÓN TERRITORIAL}

El artículo 69.1 de nuestra carta Magna establece que el Senado es la Cámara de representación territorial del Estado, lo que ha venido a comprenderse, como es lógico, como que el Senado se establece como la Cámara de representación de los intereses de las Comunidades Autónomas ${ }^{10}$, dado que éstas son las que han asumido la posición de descentralización políticoterritorial del país.

Pero esta concepción del Senado como Cámara de representación territorial es claro que, a día de hoy, no se ha logrado plenamente, y ello ha sido apuntado de manera incansable por la doctrina y por las distintas formaciones políticas, lo que ha convertido el tema de la reforma de esta Institución es una cuestión planteada prácticamente desde la aprobación de nuestra Constitución ${ }^{11}$. Especial relevancia tuvo al respecto la Moción aprobada por el Pleno del Senado el 28 de septiembre de 1994, por la que se constituía una Ponencia para estudiar, como señalaba la propia Ponencia, «las modificaciones necesarias para integrar más adecuadamente la Cámara territorial en el desarrollo del Estado de las Autonomías».

Sin embargo, esta profunda reforma del Senado no ha llegado a operarse todavía, lo cual ha podido deberse a diferentes causas: falta de consenso en la forma o el alcance de la reforma; situación política poco propicia para llegar a este gran pacto, al existir otros temas de fuerte confrontación entre partidos; los recelos del partido en el Gobierno, dado que la reforma requeriría modificar la propia Constitución, con la correspondiente disolución de las Cortes Generales y la finalización anticipada de la legislatura; así como otras que, de un modo u otro, han impedido que tal reforma se llevase a cabo.

\footnotetext{
${ }^{10}$ En este sentido, entre otros, Alonso DE ANTonio, J., Estudios sobre la reforma del Senado. Autoedición, Madrid, 1999, p. 41

${ }^{11}$ Pueden verse, entre otros, AguiAR DE Luque, L., La reforma del Senado, Madrid, Centro de Estudios Constitucionales, Senado, 1994; Martínez Sospedra, M., La reforma del Senado, Fundación Universitaria San Pablo-CEU, Valencia, 1990; Visiedo MAZón, F. J., La reforma del Senado: territorialización del Senado. Comisión General de las Comunidades Autónomas, Senado, Madrid, 1997; o Punset, R., El Senado y las Comunidades Autónomas, Tecnos, Madrid, 1987.
} 
Lo que es indudable es que en el caso español, como todo estado de conformación descentralizada y con un flujo de poder eminentemente centrífugo, la Cámara Alta no puede limitarse, como en nuestro Senado ocurre, a ser una mera reproducción de las mayorías políticas existentes en el Congreso de los Diputados, pero con menos capacidad de decisión, sino que ha de regirse por unos principios concretos, principios que podrían concretarse en los siguientes ${ }^{12}$ :

A) Cooperación: Entendida como el ejercicio de una soberanía compartida, pero no regida por una confrontación de intereses entre el Estado y los territorios o entre los territorios entre sí, sino como una fórmula de colaboración. Pero no sólo ello, pues el principio de colaboración se apoya en la diversidad, diversidad dentro del todo, la cual conforma lo que ha venido a denominarse como «Estado compuesto $»^{13}$, y evoca un tipo de relaciones horizontales

B) Participación: entendida como el cauce propio de las Comunidades Autónomas para participar en la formación de la voluntad general, principio éste que requiere para su efectiva puesta en práctica de unos mecanismos institucionales adecuados, siendo el idóneo entre todos ellos el Senado

C) Lealtad: la cual debe operar entre los distintos territorios y entre estos y el Estado, pero tal lealtad requeriría, igualmente al caso anterior, unos mecanismos institucionalizados para hacerla efectiva, siendo igualmente el Senado el lugar adecuado para ello, siempre, claro está, que la composición, competencias y funciones del mismo se adapten para hacer frente al reto que todo lo dicho hasta ahora supone

Así las cosas, la doctrina ha apuntado una serie de modificaciones o cambios a introducir en el futuro Senado a los efectos de lograr la tan deseada territorialización del mismo, y para que ello sea así deben lograrse una serie de objetivos con dicha modificación, a saber ${ }^{14}$ :

- El Senado ha de servir para instrumentar la presencia de los intereses de las Comunidades Autónomas.

- El Senado ha de servir igualmente para integrar a las Comunidades Autónomas en el funcionamiento del Estado.

- El Senado ha de servir de garantía de participación de las Comunidades Autónomas en las decisiones del Estado que les afecten especialmente.

\footnotetext{
${ }^{12}$ Ruiz-Gallardón, A., «Reflexiones sobre posibles perspectivas para una reforma constitucional del senado», en VV.AA., La reforma del Senado, Senado, Madrid, 1994, pp. 230 y ss.

${ }^{13}$ En este sentido es interesante ver la jurisprudencia constitucional sobre la materia, por todas STC 27/ 1983.

14 VinTró CASTElls, J., «Una propuesta sobre la composición y las funciones del Senado», en VV.AA., El Senado, cámara de representación territorial, Ed. Tecnos, Madrid, 1996, p. 186.
} 


\section{EL USO DE LAS LENGUAS COOFICIALES EN EL SENADO ESPAÑOL}

- El Senado ha de convertirse en el principal foro de acuerdo entre el Estado y las Comunidades Autónomas, a los efectos de solventar en su seno los posibles conflictos que se plateen.

- El Senado puede convertir en la Institución en la que se reconozcan de manera fehaciente los hechos diferenciales de las distintas Comunidades Autónomas, sin que ello signifique, claro está, que tales hechos diferenciales deban limitarse únicamente a esta Institución.

Entre las propuestas de reforma apuntadas por la doctrina a lo largo de estos años, tendentes a lograr los objetivos que acaban de ser apuntados, merece la pena destacar cuales han sido las principales de ellas, pudiendo determinarse que las mismas se han referido a los cuatro grandes elementos conformadores o propios del Senado, a saber: a) su naturaleza; b) su composición; c) sus funciones y d) su organización. Agrupadas en estos cuatro bloques las principales propuestas apuntadas, y expuestas de un modo sintético, serían las siguientes:

\section{Naturaleza}

- Naturaleza eminentemente autonómica, donde ésta sustituiría a la provincia como circunscripción electoral. De hecho se aboga por una representación exclusiva de Comunidades Autónomas.

- Introducir cambios que hagan que se evolucione hacia un bicameralismo perfecto, o al menos que se equilibren las fuerzas en materias de especial incidencia autonómica.

- Tendencia a una cámara permanente con renovaciones parciales con cada nuevas elecciones autonómicas.

\section{Composición}

- Respecto al sistema de elección de los senadores, se aboga desde fórmulas de elección directa, similares a las actuales, hasta fórmulas de designación por el Parlamento o Gobierno autonómico correspondientes.

- Respecto a la distribución de escaños, principalmente se apuesta por poner en relación el número de los mismos con la población de cada Comunidad Autónoma, estableciéndose un número mínimo.

- Se apunta la posibilidad de establecer como senadores natos a los presidentes autonómicos correspondientes.

- Respecto a la existencia o no de mandato imperativo, éste parece solamente aconsejable si se aboga por senadores directamente designados por el ejecutivo autonómico, no así en caso contrario.

\section{Funciones}

- El Senado podría convertirse en Cámara de primera lectura para aquellos temas que se determinen como de relevancia autonómica. Si bien 
ha llegado a apuntarse la posibilidad de que se configurase como cámara exclusiva para tales temas Permanecería como cámara de segunda lectura en los temas de incidencia general.

- También se ha planteado la posibilidad de establecer un veto insuperable en favor del Senado en casos de especial trascendencia autonómica en favor del Senado. Llegando a apuntarse incluso que tal veto podría corresponder de manera individual a alguna Comunidad Autónoma que entendiese que la ley afectase especialmente a alguno de hechos diferenciales.

- Se ha apuntado mayoritariamente la posibilidad de establecer un Senado sin labor de control al Gobierno de la nación, lo cual, por otra parte, podría ser el correlato de la imposibilidad de disolver la Cámara por parte del Presidente del Gobierno si la misma se configurase como una Cámara permanente.

- El Senado se convertiría en la cúspide de los sistemas de colaboración interautonómicos y con el Estado. Dando cabida, a su vez, a la resolución de los conflictos que entre estos actores pudieran suscitarse.

- A su vez, el Senado tendría la función de instrumentalizar la participación de las Comunidades Autónomas en las relaciones del Estado con la Unión Europea, y en la formación de la voluntad estatal respecto a temas europeos de incidencia autonómica

- Seguiría ejerciendo otras funciones importantes como la participación en la elección de determinados miembros de los órganos constitucionales del estado, con el correspondiente aporte de la sensibilidad autonómica en la toma de tales decisiones

\section{Organización}

- Una de las grandes propuestas en este sentido es la de establecer grupos territoriales en exclusiva, pero dada la tradición política española ello parece inviable, siendo más factible el establecimiento de dobles grupos: políticos, por un lado, y territoriales, por otro. Ello podría conjugarse con un sistema de dobles mayorías.

- Poco se ha dicho sobre los órganos de gobierno de la Cámara, salvo la posibilidad de, si se tratase de una Cámara permanente, establecer un sistema rotativo de presidencia.

- Existe acuerdo prácticamente unánime en que sería muy positivo que pudiesen utilizarse las diferentes lenguas cooficiales en el Senado, si bien no existe tanto acuerdo sobre la extensión e intensidad de tal uso.

Baste apuntar para concluir este apartado, aunque a ello dedicaremos el siguiente, que este acuerdo unánime comentado respecto al uso de las lenguas cooficiales en el Senado español, ha tenido una evolución errática hasta nuestros días, siendo identificada más como una fórmula simbólica que como una verda- 
EL USO DE LAS LENGUAS COOFICIALES EN EL SENADO ESPAÑOL

dera herramienta de avance hacía la caracterización autonómica de nuestra Cámara Alta. A reflexionar sobre ello dedicaremos el siguiente apartado.

\section{LAS LENGUAS ESPAÑOLAS COOFICIALES Y SU USO EN EL SENADO}

En este apartado vamos a abordar directamente el objeto principal del presente estudio, objeto que no es otro que la reflexión sobre del régimen vigente en la actualidad en el Senado español respecto al uso oficial en el mismo de otras lenguas distintas al castellano. Para ello, comenzaremos haciendo un breve recorrido por los diferentes momentos vividos en esta materia, aportando posteriormente opiniones y argumentos al debate, para poder llegar a comprender cual es el régimen actualmente en vigor y cuales son las posibles perspectivas de futuro que el tema del uso de las lenguas cooficiales en el Senado español presenta.

\section{Breve recorrido histórico}

\section{A) Antes de la aprobación de la Constitución de 1978}

Con carácter previo al periodo democrático que ahora vivimos, surgido tras transición acaecida en nuestro Estado a finales de los años setenta del siglo pasado, no hubo nunca un reconocimiento formal de la posibilidad de utilizar en las Cortes lenguas españolas distintas al castellano. De hecho, las sensibilidades lingüísticas diferentes al castellano únicamente recibieron cierta acogida en la Constitución republicana de 1931, donde su artículo 4 establecía que «el castellano era el idioma oficial de la República», señalando en el segundo apartado de dicho precepto que «todo español tiene obligación de saberlo y derecho de usarlo, sin perjuicio de los derechos que las leyes del Estado reconozcan a las lenguas de las provincias o regiones». Este reconocimiento de «las lenguas de las provincias o regiones» no tuvo, sin embargo, acceso al Senado, pues las Cortes republicanas eran unicamerales. Pero tampoco en el Congreso de los Diputados de la época tuvo incidencia alguna este reconocimiento del resto de las lenguas españolas, lo cual se debió quizás a que no hubo tiempo suficiente para que madurasen las sensibilidades linguiísticas, o quizás respondió a otras motivaciones de diversa índole, lo cierto es que no se realizaron manifestaciones políticas al respecto.

\section{B) Aprobación de la Constitución de 1978}

Con la aprobación de la Constitución de 1978, y como ya ha sido comentado más arriba, se inauguró un nuevo tiempo para las lenguas y culturas regionales españolas, sobre todo al amparo de reconocimiento explícito de la posible cooficialidad de las mismas contenido en el artículo 3 de nuestra 
Carta Magna y en la recepción hecha al respecto por los Estatutos de Autonomía de varias Comunidades Autónomas.

Así y todo, no se incluyó ninguna referencia en el texto constitucional respecto al uso de esas lenguas en el seno de la vida parlamentaria nacional. Ni tan siquiera en una Institución como el Senado, configurado por la propia Constitución, en su artículo 69.1, como la Cámara de representación territorial del Estado.

Tampoco se recogió esta posibilidad en el Reglamento del Senado, aprobado en sesión del Pleno el 26 de mayo de 1982, donde ninguna referencia se hizo en este sentido. Por supuesto, es lógico pensar que si el Senado, considerado como Cámara territorial del Estado, no recogía en su Reglamento referencia alguna al uso de las lenguas propias de los territorios, tampoco el Reglamento del Congreso incluiría manifestación alguna al respecto.

Pero es más, las propuestas que fueron presentadas durante este tiempo y que pretendían básicamente la incorporación a las Cortes, principalmente al Senado, de las lenguas declaras cooficiales, fueron rechazadas, algunas de ellas, incluso, sin tan siquiera ser admitidas a trámite por la Mesa correspondiente.

En este sentido merece especial atención el caso de la moción presentada por Convergencia i Unió en 1988 en el sentido de poder utilizar en el Senado las diversas lenguas cooficiales. Tal moción no fue admitida a trámite por Acuerdo de la Mesa del Senado de 10 de octubre de 1988, a lo que el grupo parlamentario promotor respondió solicitando la reconsideración de la moción, siendo rechazada igualmente por Acuerdo de la Mesa de 15 de noviembre de 1988. La negativa de la Mesa del Senado a admitir la presentación de la moción significaba que la misma no sería siquiera sometida a la consideración de los senadores, hurtándose así la posibilidad de toma de posición de los mismos al respecto.

La negativa de la Mesa del Senado se fundamentaba sustancialmente en su apreciación de que el contenido de la moción era inconstitucional por transgredir lo previsto sobre las lenguas oficiales del Estado en el art. 3 de la Constitución y en los preceptos concordantes de los Estatutos de Comunidades Autónomas con lenguas propias, de forma que la Mesa consideraba que la moción discutida intentaba una reforma constitucional fraudulenta o encubierta sin respetar lo previsto para el procedimiento de revisión constitucional en el Título X de la Norma Suprema y en el Título V del Reglamento del Senado.

Por su parte, el miembro de Convergencia i Unió que presentó la moción, entendía que la inadmisión de la misma suponía un ataque a los derechos fundamentales de igualdad (artículo 14 CE), defensa (24.1 CE) y ejercicio libre de su cargo público (23.2CE), por lo que solicitó amparo ante el Tribunal Constitucional. 
El Tribunal le concedió el amparo solicitado, y lo hizo en los siguientes términos (Fundamento Jurídico $7^{\circ}$ ): el intérprete máximo de nuestra Constitución afirmó que con el mero estudio preliminar que hizo la mesa de las mociones presentadas en modo alguno pudo llegar a entender que la misma era de contenido manifiestamente inconstitucional, dada la complejidad que el ordenamiento lingüístico español presenta, complejidad que se manifiesta, en palabras de propio Tribunal, «no sólo por las dificultades para precisar el alcance de los mandatos constitucionales y legales que versan sobre esta cuestión (y que han dado lugar a diversas resoluciones de este Tribunal) sino también por incidir sobre materias de considerable importancia, simbólica y afectiva, en la estructuración autonómica del Estado. Esta complejidad (que se ha traducido, como se ha dicho, en no pocos litigios constitucionales) hace difícil admitir que una moción como la presentada (...) resulte tan inequívocamente inconstitucional que justifique su inadmisión a limine por la Mesa del Senado. Por el contrario, el carácter inconstitucional de su contenido no resulta en modo alguno manifiesto e indubitado, en un juicio liminar, como es el que corresponde efectuar a la Mesa».

En cualquier caso, y como bien afirmaba el propio Tribunal en su Fundamento Jurídico $8^{\circ}$, la concesión del amparo solicitado no tuvo efectos prácticos, pues la legislatura en la que se presentó la moción ya había acabado y con ello habían decaído todas las propuestas, por lo que el uso de las lenguas cooficiales en el Senado no fue debatido en el Pleno. Pero no obstante, se logró iniciar un debate informal sobre la citada moción, y distintas sensibilidades políticas comenzaron a manifestarse proclives a la incorporación, si bien con una efectividad meramente simbólica, de las lenguas cooficiales al Senado.

En momentos cercanos en el tiempo a la inadmisión de la moción de Convergencia i Unió que acabamos de comentar, sí fue admitida a trámite, por Acuerdo de la Mesa del Congreso de los Diputados de 29 de septiembre de 1988, una proposición de Ley del Grupo Parlamentario Vasco sobre «Participación de la Administración del Estado en la normalización de las lenguas de las nacionalidades y regiones». Tal proposición de Ley recogía, en su artículo 8, el siguiente tenor: «En las Cortes Generales, en tanto que instituciones de representación de todos los ciudadanos del Estado, se establecerán servicios permanentes de traducción que atiendan tanto los debates parlamentarios como los trabajos y publicaciones de las Cámaras». La Sesión Plenaria del Congreso de 18 de abril de 1989 rechazó la toma en consideración de la proposición, pero antes de ello tuvo lugar el correspondiente debate, el cual sirvió, como ocurriese con la propuesta de Convergencia i Unió, para dar muestras de la existencia de una aspiración social que pugnaba por abrirse paso y ser reconocida e institucionalizada.

Paradójicamente, en fechas muy cercanas, el Pleno del Senado aprobaba, de manera unánime, la moción suscrita el 12 de diciembre de 1989 por la cual establecía el mandato de «la formulación de una propuesta consensuada de Reforma del Reglamento de la Cámara en orden a potenciar de forma más 
satisfactoria sus funciones de representación territorial». Tal acuerdo establecía como principales puntos a incluir en la citada reforma los siguientes:

«1. El desarrollo del Estado de las Autonomías reclama y permite la reforma del Senado, para potenciar su función territorial.

2. Tal reforma ha de ser adoptada mediante la correspondiente modificación del Reglamento de la Cámara.

3. (...) El objeto prioritario de la reforma del Reglamento del Senado será la promoción de la presencia en él de las instituciones autonómicas.

4. En el Senado se crearán aquellos órganos que resulten necesarios a fin de permitir y potenciar la presencia y participación de las instituciones autonómicas en los trabajos de la Cámara.

5. Entre las funciones de estos órganos (...) estará la de promover el estudio, tramitar, debatir, informar y dictaminar, en cada caso, sobre cuantos asuntos de interés autonómico hayan de conocer las Cortes.

6. La participación de los representantes de las instituciones autonómicas en los trabajos de un órgano senatorial no podrá ser imperativa.

7. En el marco de esta reforma reglamentaria, se estudiará la posibilidad del uso, en las actividades parlamentarias del Senado, de las lenguas que, además del castellano, tengan la condición de oficiales en el territorio de Alguna Comunidad Autónoma, de acuerdo con la Constitución y los correspondientes Estatutos de Autonomía».

Vemos como la cuestión del uso de las lenguas autonómicas cooficiales en el Senado había logrado entrar ya en el debate de la reforma del mismo, sin perjuicio de las evidentes dificultades a las que tal cambio habría de hacer frente y a la extensión que finalmente tuviera en realidad este uso en el día a día de la Cámara.

La finalización de la legislatura hizo decaer este trabajo parlamentario, el cual, sin embargo, fue retomado tiempo después en el siguiente periodo de mandato senatorial. Así, el Boletín Oficial de las Cortes Generales de 22 de octubre de 1993, publicaba una propuesta de reforma del Reglamento del Senado basada en las premisas apuntadas en 1989, si bien no incluía ninguna referencia al uso de las lenguas cooficiales en las actividades parlamentarias del Senado.

Finalmente estos trabajos dieron lugar a la aprobación de la reforma del Reglamento del Senado de 3 de mayo de 1994.

\section{C) La reforma del Reglamento del Senado de 3 de mayo de 1994}

En el Boletín Oficial de las Cortes Generales de 9 de mayo de 1994 aparecía publicado el Texto Refundido del Reglamento del Senado aprobado por el Pleno el 3 de mayo de 1994.

Se procedió a esta reforma del Reglamento del Senado principalmente para introducir en el funcionamiento del mismo mayores niveles de territorialización 
y de representación de las Comunidades Autónomas en los trabajos de la Cámara, pues ello era, como ya ha sido comentado, una demanda creciente de la doctrina y de gran parte de la clase política española, demanda que, si bien en principio, parecía requerir una modificación constitucional, intentó ser satisfecha por medio de la reforma reglamentaria, mientras dicha modificación constitucional no se operaba.

Esta reforma reglamentaria fue bien acogida en general, sin perjuicio de que determinadas voces apuntasen la escasa incidencia de la reforma, y otras pusiesen en duda la constitucionalidad del cambio.

Respecto al uso de las lenguas cooficiales en el Senado, si bien los trabajos parlamentarios iniciales no lo habían contemplado, la reforma del Reglamento del Senado finalmente aprobada el 3 de mayo de 1994 sí incorporó las siguientes referencias:

a) Artículo 11.bis: «En su primera intervención ante el Pleno de la Cámara, el Presidente podrá utilizar el castellano y las demás lenguas que tengan el carácter de oficiales de alguna Comunidad Autónoma, de acuerdo con la Constitución y el correspondiente Estatuto de Autonomía. En este supuesto el contenido de dicha intervención será idéntico en las diferentes lenguas».

b) Artículo 62, que finalmente fue incorporado como el 56.bis 7. Reproducimos en segundo apartado que es el que resulta de mayor interés a nuestro estudio: «Las intervenciones que se produzcan en esta sesión (Debate sobre el estado de las Autonomías) de la Comisión General de las Comunidades Autónomas podrán realizarse en cualquiera de las lenguas que, junto al castellano, tengan el carácter de oficiales en alguna Comunidad Autónoma, de acuerdo con la Constitución y el correspondiente Estatuto de Autonomía. En el Diario de Sesiones se reproducirán todas íntegramente en castellano y en la lengua en que se hayan realizado».

c) Disposición Adicional Cuarta: «Los ciudadanos y las Instituciones podrán dirigirse por escrito al Senado en cualquiera de las lenguas españolas que, junto con el castellano, tenga carácter oficial en su Comunidad Autónoma. En este supuesto la Cámara facilitará la traducción a efectos de su correspondiente tramitación».

Las tres referencias que se incluían por primera vez en el Reglamento del Senado se ceñían a momentos puntuales dentro del devenir parlamentario, teniendo por ello un componente más simbólico que efectivo, pero suponían una innovación sin precedentes, pues, con la incorporación del derecho a utilizar en una Institución central del Estado las lenguas españolas cooficiales, aunque fuera de un modo restringido, se producía el reconocimiento claro y expreso de la relevancia de las mismas, y con ello se constataba la realidad heterogénea propia de la organización de nuestro Estado. 
La primera de las medidas (artículo 11.bis) lo que permitía básicamente era que el Presidente de la Cámara, en su presentación como tal a la misma, pudiera realizar «un gesto» al Pleno, o al menos a parte de él, dirigiéndose a éste en alguna de las lenguas cooficiales.

La segunda medida, inserta dentro del trabajo de la Comisión General de las Comunidades Autónomas, se refería no, como parecería lógico, a los trabajos de esta Comisión, sino únicamente a las intervenciones en el Debate sobre el Estado de las Autonomías, lo cual, no deja de resultar, cuanto menos, complicado de justificar.

Respecto a la tercera medida debe señalarse que la misma, en puridad, no afecta directamente al trabajo parlamentario, dado que es un derecho que se establece en favor de la ciudadanía en general no de sus representantes políticos en el Senado en particular.

En todo caso, este nuevo hito del derecho lingüístico que supuso la introducción de las lenguas cooficiales en el Senado, suscitó todo tipo de opiniones contrapuestas, a las cuales nos referiremos más adelante ${ }^{15}$, siendo las principales las que se planteaban la utilidad, e incluso, la constitucionalidad de la medida, frente a aquellos que entendía excesivamente simbólico y poco efectivo el régimen del uso de las lenguas cooficiales.

Éstos últimos continuaron planteando sus reivindicaciones respecto a la escasa incidencia real del régimen dado al uso de las lenguas cooficiales en el Senado, siendo muestra de ello, entre otras, la moción presentada poco después de la reforma por un senador de Eusko Alkartasuna ${ }^{16}$, en la que se instaba el impulso, apoyo y protección de la realidad pluricultural y plurilingüe del Estado español, afirmando dicha propuesta que ello, llevado al Senado, «debe conllevar la aceptación del principio de multilingüismo integral y por tanto considerar oficiales a todos los efectos, todas las lenguas que en este Estado son oficiales».

Propuestas políticas de este tipo fueron compaginándose con una cada vez mayor presencia del elemento lingüístico en la legislación que aprobaban los Órganos centrales, siendo un hecho de especial relevancia la aprobación del Real Decreto 489/1997 de 14 de abril de 1997 sobre publicación de las Leyes en las lenguas cooficiales de las Comunidades Autónomas. Pero todo ello no llegó a provocar el cambio deseado, es decir, la ampliación del régimen de uso de las lenguas españolas cooficiales en el Senado.

Durante las Legislaturas habidas desde la reforma del Reglamento del Senado de 1994 hasta el inicio de la VIII Legislatura, el debate sobre una posible ampliación del uso de las lenguas españolas cooficiales en el Senado no volvió a tomar fuerza, como tampoco lo hizo en general la necesaria Reforma constitucional del Senado. Pero en la VIII legislatura reapareció el

\footnotetext{
${ }^{15}$ Véase en el apartado IV.2 del presente trabajo.

${ }^{16}$ Boletín Oficial de las Cortes Generales de 6 de octubre de 1994. Moción 72.
} 
debate sobre la territorialización del Senado, reapareciendo, así mismo, compañeros inseparables de viaje de tal debate, tales como el aumento del peso de las Comunidades Autónomas en los procesos legislativos a través de su mayor presencia en el Senado, la modificación de los sistemas de adscripción de escaños, o el uso de las lenguas cooficiales en los órganos centrales, especialmente en el Senado.

El Presidente del Senado en esta VIII Legislatura, Javier Rojo, en su discurso $^{17}$ de presentación al Pleno, manifestó su intención de que durante su mandato se procediera a la tan reclamada reforma constitucional de Senado, realizando, además un gesto digno de mención, como fue la utilización en su discurso de una frase en euskera ${ }^{18}$, otra en catalán/valenciano ${ }^{19}$ y otra en gallego ${ }^{20}$.

$\mathrm{Y}$ bien como un paso previo a la citada reforma constitucional, o bien como respuesta ante la difícil ejecución final de la misma y, en todo caso, como respuesta a la demanda existente y planteada desde diversas instancias y sensibilidades, el 23 de junio de 2005 se registró la «Propuesta de reforma del Reglamento del Senado sobre la ampliación del uso de las lenguas cooficiales en el Senado».

\section{D) Reforma del Reglamento del Senado sobre la ampliación del uso de las lenguas cooficiales en el Senado de 4 de julio de 2005}

Tras seguir el trámite parlamentario correspondiente, y sin que fueran aceptadas las modificaciones propuestas durante dicho trámite por CIU, PNV y BNG, a las que después nos referiremos, en el Boletín Oficial del Estado de 5 de julio de 2005 se publicaba la Reforma del Reglamento del Senado sobre la ampliación del uso de las lenguas cooficiales en el Senado.

En la exposición de motivos de la citada reforma se explicaba que la misma afrontaba «la necesidad de profundizar en el reconocimiento de la pluralidad lingüística del Estado español mediante su desarrollo en una Institución, como es el Senado, que el artículo 69.1 de la Constitución define como la Cámara de representación territorial, ampliando en su seno el uso de las lenguas cooficales».

Como vemos, puede apreciarse una clara evolución entre los planteamientos iniciales de la cuestión y las manifestaciones realizadas en la exposición de motivos que acaba de referirse. Se aprecia un indudable avance en la sensibilidad política respecto a la existencia, junto al castellano, de otras lenguas

\footnotetext{
${ }^{17}$ Discurso accesible en la dirección electrónica: http://www.senado.es/presidente/discurso.pdf.

${ }^{18}$ Nik ez dakit, euskeraz. Baiña, euskeraz esan nahi dut: Pakea Orain, eta betirako. La paz hoy y para siempre, éste es el sueño para todos los vascos.

${ }^{19}$ El Senat ha estat sempre obert al món. El Senado ha estado siempre abierto al mundo.

${ }^{20}$ O Senado debe servir de instrumento para facilitar o entendemento entre elas, achegar realidades complexas cuya expresión se basa en formas distintas de ver las cosas.
} 
igualmente oficiales, al menos en sus ámbitos geográficos concretos, que merecían, a opinión del legislador, un mayor régimen de uso y reconocimiento en una Institución, como el Senado, destinada a ser el foro de encuentro de los entes autonómicos.

Las novedades incluidas por esta modificación reglamentaria fueron las siguientes:

a) Se eliminó el segundo apartado del artículo 56 bis 7, que limitaba el uso de las lenguas cooficiales distintas al castellano en el seno de la Comisión General de las Comunidades Autónomas únicamente a las intervenciones durante el Debate sobre el Estado de las Autonomías, ampliando el uso de tales lenguas a todas las intervenciones: «Las intervenciones que se produzcan en las sesiones de la Comisión General de las Comunidades Autónomas podrán realizarse en cualquiera de las lenguas que, con el castellano, tengan el carácter de oficiales en alguna Comunidad Autónoma, de acuerdo con la Constitución y el correspondiente Estatuto de Autonomía. En el Diario de Sesiones se reproducirán íntegramente en la lengua en que se hayan realizado y en castellano».

b) La segunda innovación consistió en permitir la publicación de las mociones, interpelaciones o preguntas en la lengua, junto al castellano, que se presenten, siempre que la misma sea cooficial. Es decir, han de presentarse en castellano obligatoriamente, y lo que se permite es su publicación en ambas lenguas, sin que se imponga obligación alguna de que la posible respuesta a la misma se realice en las dos lenguas. En este sentido la reforma añadió un apartado 2 al artículo 191 del Reglamento que dice: «Si el autor de una moción, interpelación o pregunta la presenta en castellano y además en una lengua que tenga el carácter de oficial en alguna Comunidad Autónoma, de acuerdo con la Constitución y el correspondiente Estatuto de Autonomía, la iniciativa se publicará también en esa lengua».

Estos dos fueron los elementos incorporados al Reglamento del Senado. Puede parecer que ello aportó poco en realidad, dado que no se incorporaron más que dos medidas, pero consideramos que ello no es así.

La primera de las modificaciones es crucial, y cumple con un criterio lógico como es el de que, si bien en la Cámara territorial del Estado no pueden utilizarse las lenguas autonómicas cooficiales en las intervenciones parlamentarias, que sí puedan usarse, al menos, en la Comisión autonómica específica.

La segunda medida, es cierto, tiene una relevancia bastante menor, pues el hecho en sí de que se permita la presentación y publicación de mociones en una lengua distinta al castellano, además de ésta, no supone más que la disponibilidad en dicha lengua de la información, sin hacer preciso, como se 
reclamaba desde los grupos nacionalistas, una obligación de respuesta en la misma lengua cooficial empleada.

Pero, aparte de lo dicho, estas dos modificaciones tienen un valor añadido que consiste en que con ellas se aumentaron unos derechos históricamente inexistentes y que, poco a poco, parece que van consolidándose.

En cualquier caso, CIU, PNV y BNG, entendieron que las modificaciones podían ampliarse, por lo que por medio de las correspondientes enmiendas propusieron:

- posibilidad de que los senadores puedan preguntar e interpelar en la lengua cooficial. Ha de recordarse que, de hecho, en la actual Legislatura, y por cuanto se refiere a las sesiones de Control, esta posibilidad es permitida por el Presidente del Senado. Se trataba, por tanto, de institucionalizar la misma;

- que todos los escritos y comunicaciones de los senadores y los grupos puedan estar redactados en lenguas autonómicas;

- incorporar las lenguas cooficiales en el material que se distribuye entre los senadores y en la información de la página web. En este sentido, y por cuanto respecta a la página web del Senado, debe decirse que únicamente algunas informaciones se presentan en lenguas distintas al castellano;

- que la respuesta a los escritos que pueden presentar ante el Senado los ciudadanos y las Instituciones sean respondidos en la misma lengua que fueron planteados, siempre que la misma tenga el carácter de cooficial en la Comunidad Autónoma correspondiente.

A modo de resumen, y para concluir este apartado, pasaremos a realizar una sucinta referencia al régimen vigente y derechos y usos reconocidos respecto al uso de las lenguas españolas cooficiales distintas al castellano en el Senado español:

- El Presidente electo puede utilizar una lengua cooficial en su primera intervención como tal ante la Cámara (11.bis).

- En todas las intervenciones que tengan lugar dentro de la Comisión General de las Comunidades Autónomas, no sólo en el debate sobre el Estado de las Autonomías, podrán utilizarse lenguas cooficiales (56.bis.9).

- Si una moción, interpelación o pregunta se presenta por un senador en una lengua cooficial, además de en castellano, la iniciativa se publicará en ambas lenguas (191.2).

- Los ciudadanos e Instituciones podrán dirigirse por escrito al Senado en cualquiera de las lenguas cooficiales españolas. 


\section{Algunas reflexiones sobre el uso de las lenguas cooficiales en el Senado español}

No puede afirmarse que, en la actualidad, en el Senado español exista un régimen de cooficialidad lingüística como el que se da en otras Cámaras Altas del mundo, como la Canadiense ${ }^{21}$ o la Belga ${ }^{22}$. También es cierto que en el caso español no se da una situación de distribución lingüística y política coincidente, dado que en nuestro país no hay zonas exclusivas de uso de una lengua u otra, como sí ocurre en los casos canadiense y belga (salvo del régimen especial de Bruselas), sino una lengua oficial para todo el territorio nacional y, en determinadas Comunidades Autónomas, otra lengua que, dentro sus límites geográficos y políticos, asume una posición de igualdad, al menos desde el punto de vista jurídico, con la extendida por todo el territorio, pero no la desplaza.

Ello nos lleva a comprender que no es posible aplicar, sin más, soluciones de cooficialidad total como las arbitradas en las Cámaras Altas de Canadá o Bélgica, dado que en estos casos existen unos actores políticos que representan comunidades lingüísticas, que a su vez lo son geográficas y políticas, y que lo son de forma exclusiva, es decir, no hay, como en el caso español, convivencia de lenguas cooficiales en un territorio concreto (salvo el caso comentado de Bruselas), sino que diferentes territorios, con una realidad lingüística propia y exclusiva, envían a sus representantes a un foro común con otros territorios con otra lengua propia y exclusiva, y ello es así, al menos en términos generales.

Y al no ser el caso español idéntico a los comentados, no pueden importarse directamente fórmulas foráneas. Podrán servir las fórmulas de derecho comparado como guía, o como ejemplo de lo que debe o de lo que no debe hacerse, pero siempre teniendo en cuenta la peculiaridad propia de nuestro Estado, y la necesaria adaptación de cualquier medida observada en el exterior.

Respecto a la utilización de la vía reglamentaria para introducir el uso de las lenguas cooficiales en la actividad parlamentaria del Senado, debe apuntarse en primer lugar que dicha opción fue acogida, sin duda, ante la poco probable reforma constitucional del Senado, lo que obligaba a buscar una salida factible ante las crecientes demandas referidas al uso de las lenguas cooficiales.

Se han planteado dudas respecto a la posible inconstitucionalidad de utilizar la modificación reglamentaria, frente a la reforma constitucional, como

\footnotetext{
${ }^{21}$ Ver la Official Languages Act [R.S., 1985, c. 31 (4th Supp.)], en concreto su artículo 4.1 en el que puede leerse: «English and French are the official languages of Parliament, and everyone has the right to use either of those languages in any debates and other proceedings of Parliament».

${ }^{22}$ Ver, entre otros, el artículo 56.1 del Reglamento del senado Belga: «La proposition doit être signée et accompagnée de développements. Elle est remise au président, soit en français et en néerlandais, soit dans l'une des deux langues au choix de son auteur. Dans ce dernier cas, le président la fait traduire».
} 
medio para introducir el uso de las lenguas cooficiales en el Senado. Tales dudas, planteadas entre otros por Punset ${ }^{23}$, se concretarían en el postulado de que el artículo 3 de la Constitución reconoce cooficialidad únicamente dentro de los territorios autonómicos correspondientes, y que, dotar de efectos legales a tales lenguas fuera de dichos límites geográficos, excede la actual configuración constitucional, por lo que el uso de las lenguas cooficiales en el Senado precisaría de una reforma constitucional y no de una «mera» modificación reglamentaria para ajustarse a derecho.

No compartimos esta posición, pues creemos que la lengua declarada estatutariamente oficial en una Comunidad Autónoma es una seña de identidad, un hecho diferencial, que por si mismo tiene suficiente entidad como para tener cabida en una Cámara parlamentaria declarada territorial, es decir, autonómica, por la propia Constitución en su artículo 69.1. Además, la autonomía de las Cámaras permite igualmente tal opción, pues «pertenece a la esfera de competencia de los reglamentos parlamentarios (...) todo lo que no trascienda el ámbito de la Cámara, es decir, todo lo que se agote en ella» abarca así «cualquier cuestión relativa a su organización y funcionamiento ${ }^{24}$, y entendemos que las lenguas que se utilizan en los trabajos de la Cámara, cuando las mismas cuentan con el correspondiente respaldo estatutario, es totalmente lícita y ajustada a derecho.

En todo caso, nos parece muy apropiado el apunte realizado por el Profesor Tomás y Valiente ${ }^{25}$ en el sentido de que si el uso de las lenguas cooficiales podía albergar alguna duda de constitucionalidad, la mejor forma de solventarla es introducir en el propio texto constitucional la posibilidad de tal uso, dejando a la regulación reglamentaria correspondiente el régimen del mismo.

Con respecto a la utilidad de la medida también hay opiniones diversas. Así, el mismo Punset afirma que, aparte de las dudas de constitucionalidad de la medida ya apuntadas, se plantea una duda respecto a la utilidad misma de tal medida dado que «disponiendo los españoles como disponemos (...) de una lengua común, [no] tiene sentido que en un órgano constitucional del Estado, que además sería un foro de representantes de diferentes Comunidades Autónomas, se pudiera, sin embargo, recurrir al uso de lenguas distintas al castellano».

Otros, sin embargo ${ }^{26}$, entienden que este es un elemento simbólico importante, el cual supondrá, sin duda, un coste funcional a la Institución, pero que

\footnotetext{
${ }^{23}$ Punset, R., «Intervención en Debate III», en VV.AA., Ante el futuro del Senado, Ed. Generalitat de Catalunya, Barcelona, 1996, p. 550.

${ }^{24}$ DíEz-PICAZo, L., La autonomía administrativa de las Cámaras Parlamentarias, Ed. Cuadernos Studia Albornotiana, Zaragoza, 1985.

${ }^{25}$ TomÁs Y VAliente, F., «Uniformidad y diversidad en la posición de las Comunidades Autónomas en el Senado», en VV.AA., Ante el futuro del Senado, op. cit.

${ }^{26}$ CARReras DE, F., «Intervención en Debate III», en VV.AA., Ante el futuro del Senado, op. cit.
} 
es perfectamente asumible como acto de integración. Algún autor ${ }^{27}$ va más allá y opina que la medida no es apropiada, pero por escasa, dado que limitar el uso de las lenguas no castellanas al Senado, Cámara subordinada al Congreso, «significa colocar las lenguas no castellanas en un ambiente un poco folclórico», aunque se asume el indudable valor de la medida.

Con respecto a la posible extensión del derecho de uso de las lenguas cooficiales al Congreso de los Diputados, debe recordarse que, en octubre de 2004, los votos del PSOE y del PP sirvieron para rechazar una propuesta realizada por el resto de partidos que pretendía que se reconociera como derecho de los Diputados el poder utilizar las lenguas cooficiales en sus labores en la Cámara Baja.

En conexión directa con la utilidad, se encuentra la extensión del derecho de uso de las lenguas cooficiales en el Senado. En este sentido baste recordar las reivindicaciones hechas por algunos partidos nacionalistas en el sentido de ampliar el uso de las mismas en los términos apuntados más arriba.

Para concluir podrían citarse otras posibles propuestas relativas al uso de las lenguas en la vida parlamentaria del Senado, entre ellas, y a modo de ejemplo:

- Posibilidad de usar las lenguas cooficiales por aquellos que acuden a declarar a una Comisión del Senado.

- Información institucional en distintos soportes.

- Iniciativas formativas para personal y parlamentarios en dichas lenguas.

- Valoración del conocimiento de las mismas en los procesos selectivos de personal al servicio de la Cámara.

- Rotulación interior del edificio.

\section{RECAPITULACIÓN Y CONCLUSIONES}

1. España es un Estado con una realidad plurilingüe reconocida constitucionalmente (art. $3 \mathrm{CE}$ ), que se expresa en la cooficialidad, junto al castellano, en los ámbito geográficos correspondientes, de las demás lenguas españolas cuando así se determine en sus respectivos Estatutos de Autonomía.

2. Esta realidad plurilingüe hace que nos encontremos ante un proceso cierto de integración de las lenguas cooficiales en la vida pública española, siendo ejemplo de ello las cada vez más habituales referencias al fenómeno lingüístico en la legislación estatal española.

\footnotetext{
${ }^{27}$ Rubio Llorente, F., «Intervención en Debate III», en VV.AA., Ante el futuro del Senado, op. cit.
} 
3. Dentro de este proceso de integración y valoración de las lenguas españolas distintas al castellano se plateó, ya postreramente, el uso de las mismas en las Instituciones centrales del Estado, principalmente en el Senado, dado el carácter territorial y de representación autonómica que el mismo tiene atribuido constitucionalmente (art. 69.1 CE).

4. La reforma constitucional del Senado es un tema que desde el inicio del actual periodo democrático, y conforme ha ido configurándose el Estado Autonómico, ha sido demandada. La citada Reforma estaría dirigida a aumentar la participación de las Comunidades Autónomas en el ejercicio de las funciones de la Cámara Alta, y a incidir de forma más clara en la organización, naturaleza y composición de la misma. Entre las diversas reformas tendentes a potencial el carácter autonómico del Senado se ha apuntado la relativa al uso de las lenguas autonómicas cooficiales en los trabajos parlamentarios de la Cámara.

5. Con anterioridad a la aprobación de la Constitución Española de 1978, únicamente la Constitución republicana de 1931 (art. 4) había hecho alguna referencia a las lenguas españolas distintas al castellano, si bien en unos niveles de reconocimiento oficial sustancialmente menores a nuestra actual Carta Magna.

6. La Constitución de 1978 sí hizo un reconocimiento de la oficialidad de las lenguas españolas distintas al castellano, si bien siempre que dicha lengua fuese oficializada en el correspondiente Estatuto de Autonomía. Ninguna referencia contiene sin embargo nuestra Carta Magna respecto al uso de tales lenguas cooficiales en el seno de los órganos centrales del Estado.

7. En un principio, la posibilidad de usar alguna lengua distinta al castellano en el Senado no fue contemplada. Así, no se incluyó en el Reglamento de la Cámara, aprobado en 1982, ninguna referencia al respecto, y fueron rechazadas algunas propuestas presentadas por diversos grupos parlamentarios en este sentido.

8. El Pleno del Senado aprobó, de manera unánime, una moción de 12 de diciembre de 1989, por la que se acordaba el inicio de los trabajos tendentes a preparar una reforma del Senado buscando aumentar el carácter territorial del mismo. Como uno de los puntos principales a tratar en la reforma se incluía el estudio de «la posibilidad del uso, en las actividades parlamentarias del Senado, de las lenguas que, además del castellano, tengan la condición de oficiales en el territorio de alguna Comunidad Autónoma, de acuerdo con la Constitución y los correspondientes Estatutos de Autonomía».

9. Tales trabajos dieron lugar no a una reforma constitucional del Senado, pero sí a una importante modificación del Reglamento del 
Senado, la cual se materializó en el Texto Refundido del Reglamento del Senado aprobado por el Pleno el 3 de mayo de 1994. En tal reforma, que pretendía aumentar el carácter autonómico del Senado, se incluyeron tres referencias al uso de las lenguas cooficiales, distintas al castellano, en la vida parlamentaria de la Cámara Alta: a) posibilidad de que el Presidente de la Cámara, en su discurso de presentación, utilice las lenguas cooficiales; b) posibilidad de usar las lenguas cooficiales en las intervenciones en el Debate sobre el estado de las Autonomías y c) posibilidad reconocida a los ciudadanos e Instituciones de utilizarlas lenguas cooficiales para dirigir escritos al Senado.

10. Esta reforma supuso un importante hito al ser la primera vez que se reconocía la posibilidad de uso de las lenguas cooficiales en un órgano central del Estado. Aún así, el régimen de uso fue tachado por muchos como insuficiente, lo que motivó que comenzase a demandarse un aumento de las posibilidades de uso que la nueva situación permitía.

11. Este debate, unido al más general de la necesaria reforma constitucional del Senado, permaneció latente hasta la llegada de la VIII Legislatura, momento en que volvió a tomar fuerza. Como ya ocurriera anteriormente, la reforma constitucional no parecía contar con los apoyos suficientes, pero volvió a promoverse una nueva modificación reglamentaria ampliando el régimen de uso de las lenguas cooficiales en el Senado. Así se aprobó la Reforma del Reglamento del Senado sobre la ampliación del uso de las lenguas cooficiales en el Senado, de 4 de julio de 2005. Las novedades incluidas en esta reforma fueron: a) ampliación de las lenguas cooficiales en su uso dentro de la Comisión General de las Comunidades Autónomas, antes limitado al Debate sobre el Estado de la Autonomías; b) posibilidad de presentar mociones, iniciativas o propuestas en otra lengua cooficial junto a la castellana, y publicación en ambas lenguas de tales escritos.

12. Sobre la Constitucionalidad de utilizar la vía reglamentaria para introducir el uso de las lenguas cooficiales en el Senado, y aunque se han planteado algunas dudas doctrinales al respecto, en ningún momento ha sido impugnada la iniciativa, contando además con la opinión favorable de la gran mayoría científica y política.

13. Respecto a la utilidad actual de la posibilidad de uso de las lenguas cooficiales en el Senado, en general se coincide en que la misma es más bien simbólica, sin perjuicio de que dicho simbolismo tiene en si mismo una función y una eficacia integradora cierta. En todo caso, existen multitud de propuestas de ampliación de este régimen de uso de las lenguas cooficales en nuestra Cámara Alta. 
14. No ha habido hasta la fecha más modificaciones del régimen de uso de las lenguas cooficiales en el Senado español. Tal régimen queda definido del siguiente modo:

- El Presidente electo puede utilizar una lengua cooficial en su primera intervención como tal ante la Cámara (11.bis).

- En todas las intervenciones que tengan lugar dentro de la Comisión General de las Comunidades Autónomas, no sólo en el debate sobre el Estado de las Autonomías, podrán utilizarse lenguas cooficiales (56.bis.9).

- Si una moción, interpelación o pregunta se presenta por un senador en una lengua cooficial, además de en castellano, la iniciativa se publicará en ambas lenguas (191.2).

- Los ciudadanos e instituciones podrán dirigirse por escrito al Senado en cualquiera de las lenguas cooficiales españolas.

15. Se han apuntado, sin embargo, otras posibles medidas que ampliarían el citado régimen de uso de las lenguas cooficiales en el Senado:

- posibilidad de que los senadores puedan preguntar e interpelar en la lengua cooficial;

- que todos los escritos y comunicaciones de los senadores y los grupos parlamentarios puedan estar redactados en lenguas autonómicas;

- incorporar las lenguas en el material que se distribuye entre los senadores y en la información de la página web.

- que la respuesta a los escritos que pueden presentar ante el Senado los ciudadanos y las Instituciones sean respondidos en la misma lengua que fueron planteados, siempre que la misma tenga el carácter de cooficial en la Comunidad Autónoma correspondiente.

16. A tales propuestas nos permitimos añadir estas otras:

- Posibilidad de usar las lenguas cooficiales por aquellos que acuden a declarar a una Comisión del Senado.

- Información institucional en distintos soportes.

- Iniciativas formativas para personal y parlamentarios en dichas lenguas.

- Valoración del conocimiento de las mismas en los procesos selectivos de personal al servicio de la Cámara.

- Rotulación interior del edificio. 


\section{BIBLIOGRAFIA}

Agutar de Luque, L., La reforma del Senado, Madrid, Centro de Estudios Constitucionales, Senado, 1994.

Alcaraz Ramos, M., El régimen jurídico de las lenguas en la Comunidad Valenciana, Universidad de Alicante, Alicante, 1999.

Alonso de Antonio, J., Estudios sobre la reforma del Senado. Autoedición, Madrid, 1999, p. 41.

Carreras De, F., «Intervención en Debate III», en VV.AA., Ante el futuro del Senado, Generalitat Valenciana, Barcelona, 1996.

Díez-Picazo, L., La autonomía administrativa de las Cámaras Parlamentarias, Ed. Cuadernos Studia Albornotiana, Zaragoza, 1985.

Martínez Sospedra, M., La reforma del Senado, Fundación Universitaria San Pablo-CEU, Valencia, 1990.

PAU i VALL, F. (coordinador), El Senado, cámara de representación territorial, Ed. Tecnos, Barcelona, 1996.

Punset, R., El Senado y las Comunidades Autónomas, Tecnos, Madrid, 1987.

Punset, R., «Intervención en Debate III», en VV.AA., Ante el futuro del Senado, Ed. Generalitat de Catalunya, Barcelona, 1996.

Rubio Llorente, F., «Intervención en Debate III», en VV.AA., Ante el futuro del Senado, Generalitat Valenciana, Barcelona, 1996.

RUIZ-GALlARDóN, A., «Reflexiones sobre posibles perspectivas para una reforma constitucional del Senado», en VV.AA., La reforma del Senado, Senado, Madrid, 1994.

Tomás y VALIENTE, F., «Uniformidad y diversidad en la posición de las Comunidades Autónomas en el Senado», en VV.AA., Ante el futuro del Senado, Generalitat Valenciana, Barcelona, 1996.

Vintró CAStells, J., «Una propuesta sobre la composición y las funciones del Senado», en VV.AA., El Senado, cámara de representación territorial, Ed. Tecnos, Madrid, 1996.

Visiedo MAZón, F. J., La reforma del Senado: territorialización del Senado. Comisión General de las Comunidades Autónomas, Senado, Madrid, 1997.

Vernet, J. (coordinador), Dret Lingüistic, Ed. Cossetània, Barcelona, 2003.

- http://www.senado.es/presidente/discurso.pdf.

- Senado de Canadá: www.parl.gc.ca.

- Senado de Bélgica: www.senate.be.

- Senado de España: www.senado.es.

- Tribunal Constitucional: www.tribunalconstitucional.es. 